\title{
The continuous strength method
}

L. Gardner MSc, PhD, DIC, CEng, MICE, MIStructE

Many of the principal concepts that underpin current metallic structural design codes were developed on the basis of bilinear (elastic, perfectly-plastic) material behaviour; such material behaviour lends itself to the concept of section classification. The continuous strength method represents an alternative treatment to crosssection classification, which is based on a continuous relationship between slenderness and (inelastic) local buckling and a rational exploitation of strain hardening. The development and application of the continuous strength method to structural steel design is described herein. Materials that exhibit a high degree of nonlinearity and strain hardening, such as aluminium, stainless steel and some high-strength steels, fit less appropriately into the framework of cross-section classification, and generally benefit to a greater extent from the continuous strength method. The method provides better agreement with test results in comparison to existing design codes, and offers increases in member resistance and a reduction in scatter of the prediction. An additional benefit of the proposed approach is that cross-section deformation capacity is explicitly determined in the calculations, thus enabling a more sophisticated and informed assessment of ductility supply and demand. Further developments to the method are under way.

\section{INTRODUCTION}

The resistance of structural cross-sections is a continuous function of the slenderness of the constituent plate elements. Resistance based on the assignment of cross-sections to discrete behavioural classes is a useful, but artificial, simplification. Most structural design codes define four classes of cross-section: class 1 (plastic), class 2 (compact), class 3 (semi-compact) and class 4 (slender). The moment-rotation characteristics and idealised bending stress distributions associated with the four classes of cross-section are illustrated in Figs 1 and 2, respectively. Class 1 cross-sections are fully effective under pure compression and are capable of reaching and maintaining their full plastic moment $M_{\mathrm{pl}}$ in bending (and may therefore be used in plastic design). Class 2 cross-sections have a somewhat lower deformation capacity, but are also fully effective in pure compression and are capable of reaching their full plastic moment in bending. Class 3 cross-sections are fully effective in pure compression, but local buckling prevents attainment of the full plastic moment in bending; bending moment resistance is therefore limited to the elastic (yield) moment $M_{\mathrm{el}}$. For class 4 cross-sections, local buckling occurs prior to yielding. The loss of effectiveness owing to local buckling (below the yield stress) is generally accounted for by the determination of effective cross-section properties based on the width-to-thickness ratios, boundary conditions and loading conditions of the individual plate elements. The resulting effective area $A_{\text {eff }}$ (for compression) and effective modulus $W_{\text {eff }}$ (for bending) is then used to determine cross-section resistance.

Although not explicitly included in the determination of resistance, strain hardening is an essential component of the described section classification system, and is required, for example, to enable the attainment of the plastic moment $M_{\mathrm{pl}}$ at finite strains. The continuous strength method represents an

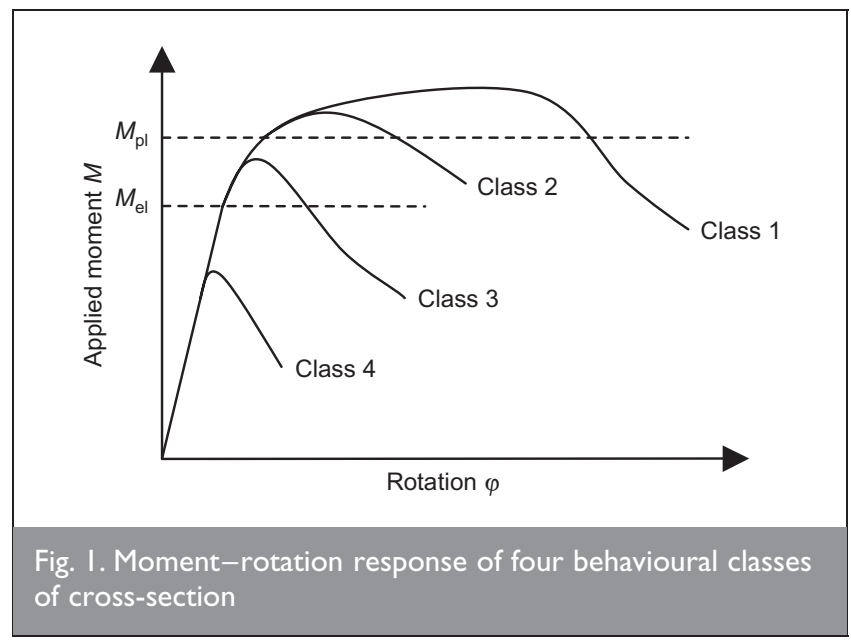

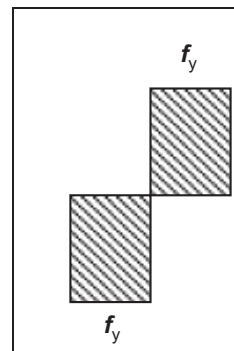

(a)

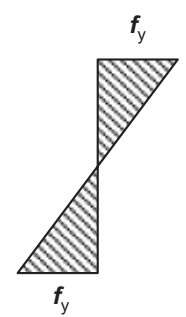

(b)

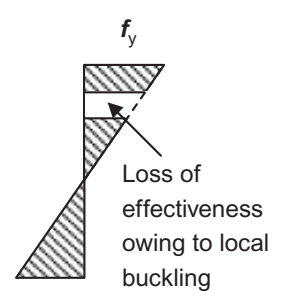

(c)
Fig. 2. Idealised bending stress distributions (symmetric section): (a) classes I and 2; (b) class 3; (c) class 4 
alternative treatment to cross-section classification, which is based on a continuous relationship between slenderness and (inelastic) local buckling and a rational exploitation of strain hardening. The development and application of the continuous strength method is described herein.

\section{CROSS-SECTION CLASSIFICATION}

To illustrate the shortcomings of cross-section classification, test data for structural steel sections in compression and bending are plotted in Figs 3 and 4 respectively. Fig. 3 shows the results of stub column tests ${ }^{1-6}$ on structural steel square and rectangular hollow sections and lipped channels. The maximum load-carrying capacity of the stub columns $\boldsymbol{F}_{\mathrm{u}}$ has been normalised by the yield load (determined as the gross cross-sectional area $A$ multiplied by the material yield strength $\boldsymbol{f}_{\mathrm{y}}$ ) and plotted against the maximum slenderness of the constituent plate elements $\bar{\lambda}_{\mathrm{p}}$, defined by equation (1)

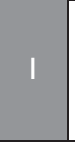

$$
\bar{\lambda}_{\mathrm{p}}=\sqrt{\frac{\boldsymbol{f}_{\mathrm{y}}}{\boldsymbol{\sigma}_{\mathrm{cr}}}}=\frac{\sqrt{12\left(1-v^{2}\right)} \sqrt{235}}{\pi \sqrt{E} \sqrt{k_{\sigma}}}\left(\frac{b}{t \boldsymbol{\varepsilon}}\right)
$$

where $\boldsymbol{\sigma}_{\mathrm{cr}}$ is the elastic critical buckling stress of the plate element, $b$ and $t$ are the plate width and thickness respectively,

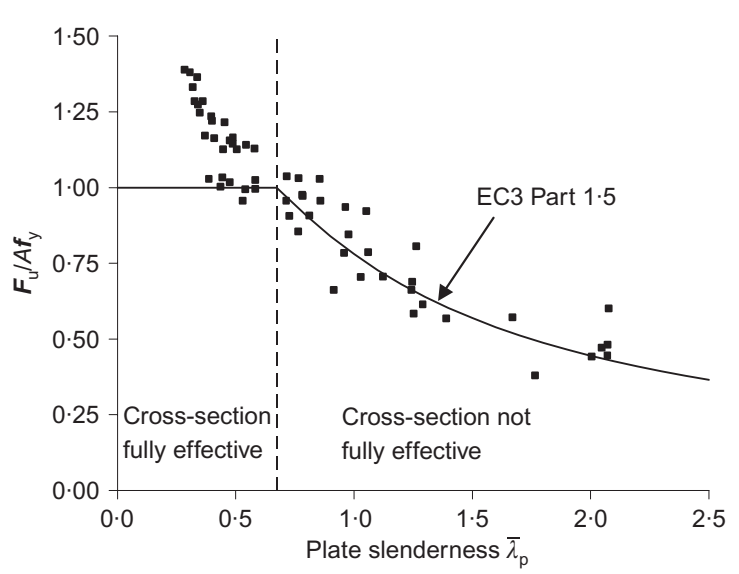

Fig. 3. Stub column test results

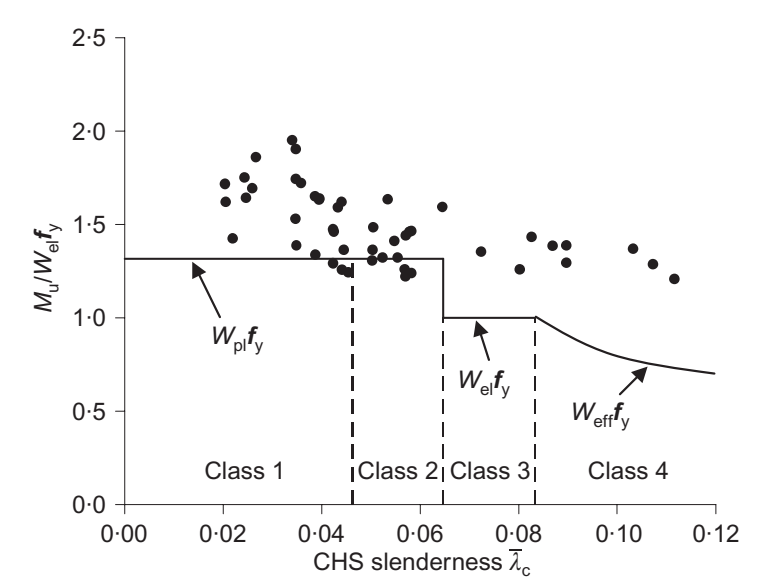

Fig. 4. CHS bending test results
$E$ is Young's modulus, $v$ is Poisson's ratio, $\boldsymbol{\varepsilon}=\left(235 / \boldsymbol{f}_{\mathrm{y}}\right)^{1 / 2}$ and $k_{\sigma}$ is the familiar buckling coefficient allowing for differing loading and boundary conditions. The slenderness limit beyond which cross-sections are deemed not to be fully effective, together with the curve representing reduction factors for loss of effectiveness from Eurocode 3, are indicated in Fig. 3, and may be seen to accord well with the test data. The test data also reveal, however, significant conservatism when the resistance of stocky cross-sections is limited to the yield load; this is attributed to the occurrence of strain hardening.

Figure 4 shows the results of bending tests on structural steel circular hollow sections (CHS). These results were collated from a series of three- and four-point bending tests. ${ }^{7-12}$ In Fig. 4, the maximum bending moment from the beam tests $M_{\mathrm{u}}$ has been normalised by the elastic moment $M_{\mathrm{el}}$ (determined as the elastic modulus $W_{\text {el }}$ multiplied by the material yield strength $\boldsymbol{f}_{\mathrm{y}}$ ) and plotted against the cross-section slenderness $\bar{\lambda}_{c}$, defined by equation (2). The Eurocode $3^{13}$ cross-section classes are also indicated in Fig. 4, where the plastic moment $M_{\mathrm{pl}}$ (determined as the plastic modulus $W_{\mathrm{pl}}$ multiplied by the material yield strength $\boldsymbol{f}_{\mathrm{y}}$ ) applies to class 1 and 2 cross-sections, the elastic moment $M_{\mathrm{el}}$ applies to class 3 cross-sections and an effective moment should be determined for class 4 cross-sections.

$$
\bar{\lambda}_{\mathrm{c}}=\frac{\boldsymbol{f}_{\mathrm{y}}}{\boldsymbol{\sigma}_{\mathrm{cr}}}=\frac{235 \sqrt{3\left(1-v^{2}\right)}}{2 E}\left(\frac{D}{t \boldsymbol{\varepsilon}^{2}}\right)
$$

where $\boldsymbol{\sigma}_{\mathrm{cr}}$ is the elastic critical buckling stress of the circular hollow section and $D$ and $t$ are the diameter and thickness of the circular hollow section respectively. Note that the adopted slenderness measure for CHS is based on the minimum elastic buckling stress of a uniformly compressed circular shell (in the axisymmetric mode). No distinction is made between loading conditions (i.e. no advantage is taken when considering less severe stress distributions than pure compression), unlike for the case of flat plates, where the buckling coefficient $k_{\sigma}$ does account for different in-plane stress gradients. This is partly for simplicity and partly owing to difficulties in assessing the resulting local buckling response, particularly in the inelastic range. A similar approach is taken in Eurocode $3,{ }^{13}$ which employs common slenderness limits for CHS in both compression and bending, though this approach has been questioned. ${ }^{14,15}$ Further investigation is under way on this matter.

Figure 4 generally indicates that the cross-section classification system is conservative and that its stepwise nature does not reflect the observed physical response.

\section{THE CONTINUOUS STRENGTH METHOD}

Many of the principal concepts that underpin current metallic structural design codes were developed on the basis of bilinear (elastic, perfectly-plastic) material behaviour; such material behaviour lends itself to the concept of section classification. The continuous strength method employs more precise material modelling. Such models reflect, for example, the strain hardening associated with hot-rolled steel sections and the characteristic rounded stress-strain behaviour of aluminium, stainless steel and some high-strength, cold-worked steels. 
In addition to accurate material modelling, a key feature of the continuous strength method is to replace the concept of crosssection classification with a continuous non-dimensional numerical measure of the deformation capacity of the crosssection. The relationship between cross-section slenderness and cross-section deformation capacity has been derived on the basis of stub column tests in compression. This relationship has been derived for steel cross-sections comprising flat plates and for circular hollow sections. The adopted measures of slenderness, $\bar{\lambda}_{\mathrm{p}}$ and $\bar{\lambda}_{\mathrm{c}}$, are given by equations (1) and (2) for plated cross-sections and circular sections respectively.

\section{I Cross-section deformation capacity}

The basic measure of cross-section deformation capacity has been derived from the end-shortening $\delta_{\mathrm{u}}$ corresponding to the ultimate load $\boldsymbol{F}_{\mathrm{u}}$ from stub column tests. Average strain at ultimate load (referred to herein as local buckling strain $\boldsymbol{\varepsilon}_{\mathrm{LB}}$ ) may subsequently be determined by dividing $\delta_{\mathrm{u}}$ by the stub column length $L$. To allow for differing material properties, the local buckling strain $\boldsymbol{\varepsilon}_{\mathrm{LB}}$ has been normalised by the elastic strain at the material yield stress $\boldsymbol{\varepsilon}_{0}$, where $\boldsymbol{\varepsilon}_{0}=\boldsymbol{f}_{\mathbf{y}} / E$. Crosssection deformation capacity will therefore be defined by the normalised local buckling strain $\boldsymbol{\varepsilon}_{\mathrm{LB}} / \boldsymbol{\varepsilon}_{0}$.

\subsection{Relationship between deformation capacity $\varepsilon_{L B}$ and} slenderness

The relationship between elastic critical buckling strain $\boldsymbol{\varepsilon}_{\mathrm{cr}}$ (normalised by the elastic strain at the material yield stress $\boldsymbol{\varepsilon}_{0}$ ) and cross-section slenderness is given by equations (3) and (4) for flat plates and circular sections respectively.

\begin{tabular}{|l|l|}
\hline 3 & $\frac{\varepsilon_{\mathrm{cr}}}{\boldsymbol{\varepsilon}_{0}}=\frac{1}{\bar{\lambda}_{\mathrm{p}}^{2}}$ for flat plates \\
\hline
\end{tabular}

\begin{tabular}{|l|l|}
\hline 4 & $\frac{\boldsymbol{\varepsilon}_{\mathrm{cr}}}{\boldsymbol{\varepsilon}_{0}}=\frac{1}{\bar{\lambda}_{\mathrm{c}}}$ for CHS \\
\hline
\end{tabular}

Buckling, however, only occurs wholly in the elastic material range for slender plates. In order to derive a relationship between deformation capacity and cross-section slenderness, equations (3) and (4) therefore have to be modified to allow for effects including inelastic buckling, imperfections, residual stresses and post-buckling behaviour. To this end, the general expression of the form given by equation (5) was adopted. The general expression is similar to that proposed for flat aluminium plates ${ }^{16}$

\begin{tabular}{|l|l|}
\hline 5 & $\frac{\boldsymbol{\varepsilon}_{\mathrm{LB}}}{\boldsymbol{\varepsilon}_{0}}=\frac{A}{\bar{\lambda}^{B+C \bar{\lambda}}}$ \\
\hline
\end{tabular}

where the coefficients $A, B$ and $C$ may be derived by regression analysis of stub column test data. The regression analysis yielded equation (6) for steel cross-sections comprising flat plates, which together with the stub column test data ${ }^{1-6}$ has been plotted in Fig. 5 .



Fig. 5. Deformation capacity-slenderness relationship for flat steel-plated cross-sections

$6 \quad \frac{\boldsymbol{\varepsilon}_{\mathrm{LB}}}{\boldsymbol{\varepsilon}_{0}}=\frac{1 \cdot 05}{\bar{\lambda}_{\mathrm{p}}^{3 \cdot 15-0 \cdot 95 \bar{\lambda}_{p}}}$

From Fig. 5 it can be seen that the tests on the plated sections generally lie above the elastic critical buckling curve, with the greatest deviation occurring for low values of $\bar{\lambda}_{\mathrm{p}}$. The regression curve shown in Fig. 5 represents the continuous relationship between cross-section slenderness and crosssection deformation capacity (equation (6)), derived from the stub column tests.

For circular sections, a regression analysis of steel CHS stub column data ${ }^{17,18}$ led to equation (7). The CHS stub column data and regression curve have been plotted in Fig. 6, together with the elastic critical buckling curve. It may be observed that, unlike for the plated sections, the CHS data points lie below the elastic critical buckling curve, reflecting the unstable postbuckling behaviour of circular tubes and the resulting sensitivity to imperfections.

\begin{tabular}{|l|l|}
\hline 7 & $\frac{\boldsymbol{\varepsilon}_{\mathrm{LB}}}{\boldsymbol{\varepsilon}_{0}}=\frac{0.07}{\bar{\lambda}_{\mathrm{c}}^{1 \cdot 51-2 \cdot 55 \bar{\lambda}_{\mathrm{c}}}}$ \\
\hline
\end{tabular}

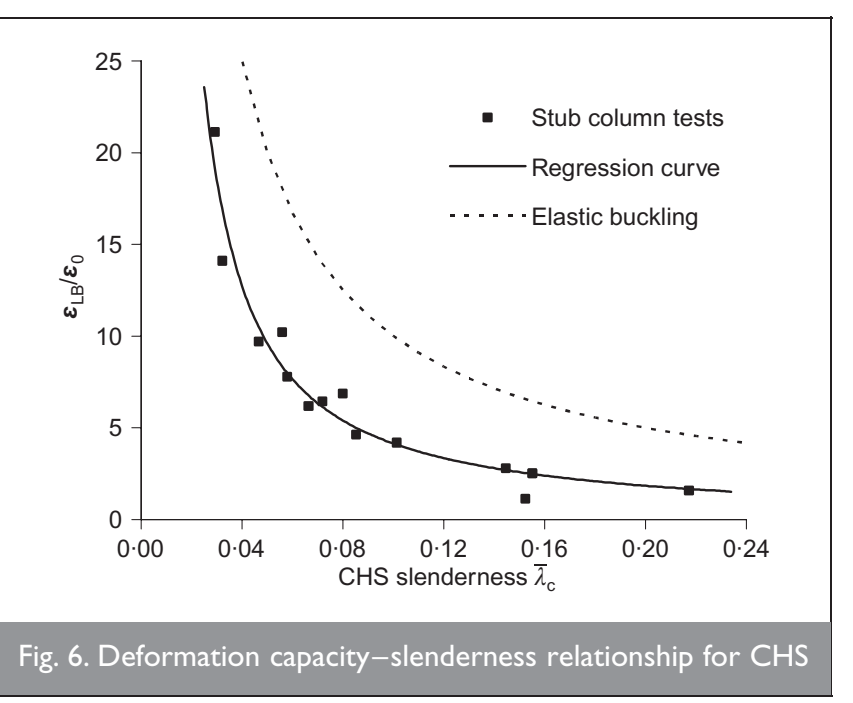


The derived slenderness-deformation capacity relationships (equations (6) and (7)) form the basis of the continuous strength method, in which the acquired deformation capacity is used in conjunction with a representative material model to determine the resistance of structural cross-sections. It should be noted that the deformation capacities for relatively slender plate sections $\left(\bar{\lambda}_{\mathrm{p}}>1\right)$ are influenced by post-buckling effects. For such sections, the peak of the load-end shortening curves does not provide an appropriate measure of deformation capacity for the proposed method, and the results were adjusted accordingly. ${ }^{19}$

\subsection{Cross-section compression resistance}

To determine cross-section resistance in compression the deformation capacity obtained using the equations developed in section 3.2 may be used directly to obtain the local buckling strength $\sigma_{\mathrm{LB}}$ of the cross-section through a representative material model. The compression resistance is subsequently determined by multiplying this local buckling strength $\sigma_{\mathrm{LB}}$ by the gross cross-sectional area $A$.

The basic design steps for cross-section compression resistance may be summarised as follows.

(a) Determine the slenderness $\bar{\lambda}_{\mathrm{p}}$ (or $\bar{\lambda}_{\mathrm{c}}$ ) for the individual elements within the cross-section; cross-section slenderness is defined by the most slender element.

(b) Use the cross-section slenderness to determine its deformation capacity $\boldsymbol{\varepsilon}_{\mathrm{LB}}$ via equations (6) or (7).

(c) Determine the corresponding local buckling stress $\sigma_{\mathrm{LB}}$ from the material stress-strain model.

(d) Cross-section compression resistance $\boldsymbol{N}_{c, R d}$ is given by the product of the local buckling stress $\sigma_{\mathrm{LB}}$ and the gross cross-sectional area $A$ (equation (8)).

$$
8 \quad \mathbf{N}_{\mathrm{c}, \mathrm{Rd}}=\sigma_{\mathrm{LB}} A
$$

\subsection{Cross-section bending resistance}

In-plane bending resistance may be calculated on a similar basis to compression resistance, whereby the deformation capacity $\boldsymbol{\varepsilon}_{\mathrm{LB}}$ of the cross-section is limited either by local buckling of the web in bending or the compression flange in pure compression. Once the outer-fibre local buckling strain limit $\boldsymbol{\varepsilon}_{\mathrm{LB}}$ has been established (following steps 1 and 2 described in the previous section), the moment resistance may be calculated by means of integration of the material model through the depth of the cross-section (equation (9)), assuming a linearly varying strain distribution.

$M_{\mathrm{c}, \mathrm{Rd}}=\int_{\mathrm{A}} \boldsymbol{\sigma} y \mathrm{~d} A$

where $y$ is the distance from the neutral axis of the crosssection.

For simple material models, such as an elastic, linear strain hardening model (described by equations (10) and (11)), explicit expressions for in-plane moment resistance in terms of the outer-fibre local buckling strain limit $\boldsymbol{\varepsilon}_{\mathrm{LB}}$ can be derived. For more complex material models, explicit expressions rapidly become unwieldy, and the concept of a generalised shape factor can be introduced. ${ }^{20}$ A generalised shape factor is essentially a means by which material as well as geometric properties of a cross-section are incorporated into a single factor. The generalised shape factor $a_{\mathrm{g}}$ can be presented in tabular form, in terms of the outer-fibre strain limit $\boldsymbol{\varepsilon}_{\mathrm{LB}}$ and the conventional geometric shape factor $a_{\mathrm{p}}$ of the crosssection. ${ }^{21,22}$ To reduce design effort, an alternative treatment whereby moment resistance is determined directly from the deformation capacity of the cross-section and the traditional elastic and plastic moment resistances is currently being developed.

\section{APPLICATION TO STEEL STRUCTURES}

In order to assess the level of enhancement in resistance offered by the continuous strength method over conventional design methods for steel structures, comparisons against the results of existing compression and bending tests were performed. Member instability does not feature in the comparisons made herein; instead cross-section resistance in compression and in-plane bending are analysed. Study of such behaviour is instructive since it represents one bound to the member resistance, to which reduction factors can be applied for member buckling. Additionally, many forms of construction provide lateral restraint to beams such that lateral torsional buckling may be neglected. Nethercot and Lawson ${ }^{23}$ discuss common cases of restraint in buildings. Kemp et al. ${ }^{24}$ examined the influence of strain hardening on the behaviour of beams, and derived a relationship between curvature and maximum bending resistance allowing for both local and lateral buckling.

In this study, the elastic, linear strain hardening material model described by equations (10) and (11) has been utilised to approximate $\boldsymbol{\sigma}_{\mathrm{LB}}$ from $\boldsymbol{\varepsilon}_{\mathrm{LB}}$ for structural steelwork.

$10 \quad \sigma_{\mathrm{LB}}=\boldsymbol{E} \varepsilon_{\mathrm{LB}}$ for $\boldsymbol{\varepsilon}_{\mathrm{LB}} \leqslant \boldsymbol{\varepsilon}_{0}$ 


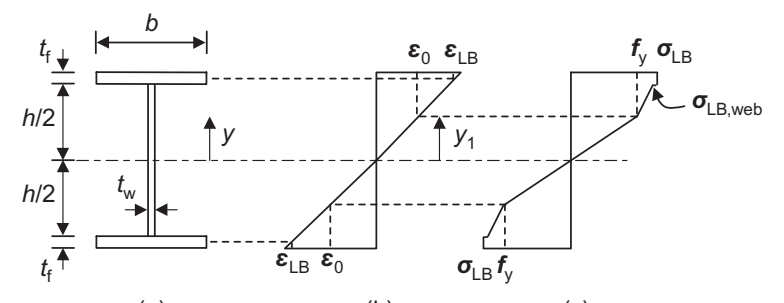

(a)

(b)

(c)

Fig. 7. Bending response of I-section with elastic, linear strainhardening material model: (a) cross-section; (b) strain; (c) stress

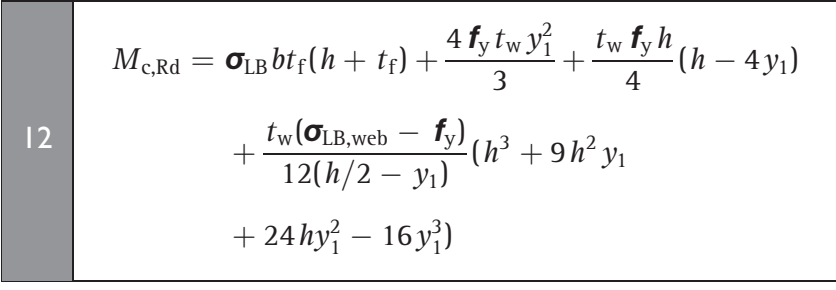

where symbols are defined by reference to Fig. 7 and $y_{1}$ may be determined from equation (13). For $\boldsymbol{\sigma}_{\mathrm{LB}}<\boldsymbol{f}_{\mathrm{y}}, M_{\mathrm{c}, \text { Rd }}$ simply reverts to that for an elastic bending stress distribution.

$$
y_{1}=\frac{\boldsymbol{\varepsilon}_{0}}{\boldsymbol{\varepsilon}_{\mathrm{LB}}}\left(h / 2+t_{\mathrm{f}}\right)
$$

For CHS, the bending resistance $M_{\mathrm{c}, \mathrm{Rd}}$ may be derived on the same basis as equation (12) for plated sections, but by integrating with respect to the angle $\theta$ around the crosssection, as described in general terms by equation (14).

\begin{tabular}{|l|l|}
\hline 14 & $M_{\mathrm{c}, \mathrm{Rd}}=4 \int_{0}^{\pi / 2} \sigma(r \sin \theta) \operatorname{tr} \mathrm{d} \theta$ \\
\hline
\end{tabular}

where $r$ is the radius of the CHS measured to the centreline of the thickness $t$, as shown in Fig. 8. For the linear, elastic strain hardening material model considered, the bending resistance $M_{\mathrm{c}, \mathrm{Rd}}$ for the case when $\boldsymbol{\sigma}_{\mathrm{LB}}>\boldsymbol{f}_{\mathrm{y}}$ is given by equation (15). As for plated sections, in the case where $\boldsymbol{\sigma}_{\mathrm{LB}}<\boldsymbol{f}_{\mathrm{y}}, M_{\mathrm{c}, \mathrm{Rd}}$ simply reverts to that for an elastic bending stress distribution.

$$
\begin{aligned}
M_{\mathrm{c}, \mathrm{Rd}}= & 4 \operatorname{tr}^{2}\left\{\boldsymbol{f}_{\mathrm{y}}\left[\frac{\boldsymbol{\varepsilon}_{\mathrm{LB}}}{\boldsymbol{\varepsilon}_{0}}\left(\frac{\theta_{1}}{2}-\frac{\sin 2 \theta_{1}}{4}\right)+\cos \theta_{1}\right]\right. \\
& +\frac{\boldsymbol{\sigma}_{\mathrm{LB}}-\boldsymbol{f}_{\mathrm{y}}}{1-\left(\boldsymbol{\varepsilon}_{0} / \boldsymbol{\varepsilon}_{\mathrm{LB}}\right)} \\
& \left.\times\left[\frac{\pi}{4}-\frac{\theta_{1}}{2}+\frac{\sin 2 \theta_{1}}{4}-\frac{\boldsymbol{\varepsilon}_{0}}{\boldsymbol{\varepsilon}_{\mathrm{LB}}} \cos \theta_{1}\right]\right\}
\end{aligned}
$$

where $\theta_{1}$ is the angle at which strain hardening begins (see Fig. 8), given by $\theta_{1}=\sin ^{-1}\left(\varepsilon_{0} / \varepsilon_{\mathrm{LB}}\right)$.

Comparisons of the continuous strength method with crosssection compression tests and in-plane bending tests are shown in Tables 1 and 2, respectively. The results have also been compared with existing design guidance. All test specimens have class 1, 2 or 3 cross-sections. Test data were sourced from

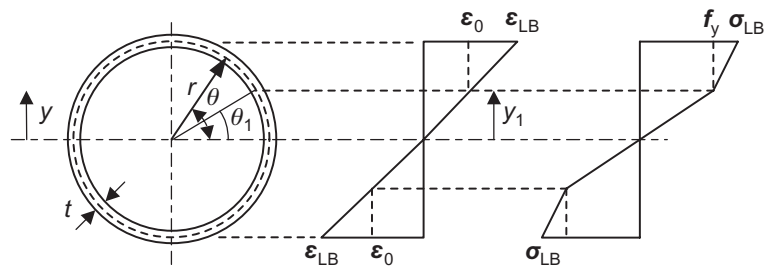

(a)

(b)

(c)

Fig. 8. Bending response of CHS with elastic, linear strainhardening material model: (a) cross-section; (b) strain; (c) stress

the references provided in section 2 and Byfield and Nethercot. ${ }^{26}$

The results show that, in all cases, the continuous strength method offers more accurate average representation of physical behaviour and a reduction in scatter. Tables 1 and 2 indicated that by adopting the continuous strength method, average increases in resistance of 12\% for compression and 15\% for inplane bending are achieved over existing methods (Eurocode 3). Although the continuous strength method is applicable over the full range of element slenderness, greater benefits over current practice are derived for stocky sections, and the response of slender sections may be more accurately predicted using an effective width ${ }^{25}$ or direct strength ${ }^{27}$ approach. Further research into application of the continuous strength method to slender cross-sections is ongoing. Extension of the method to cover shear resistance and hence combined bending and shear is also currently under way.

\begin{tabular}{lcccc}
\hline $\begin{array}{l}\text { Section } \\
\text { type }\end{array}$ & $\begin{array}{c}\text { Number } \\
\text { of tests }\end{array}$ & $F_{\mathrm{u}, \text { test }} F_{\mathrm{u}, \mathrm{EC} 3}$ & $\boldsymbol{F}_{\mathrm{u}, \text { test }} / \boldsymbol{F}_{\mathrm{u}, \mathrm{CSM}}$ & $\boldsymbol{F}_{\mathrm{u}, \mathrm{CSM}} / \boldsymbol{F}_{\mathrm{u}, \mathrm{EC} 3}$ \\
\hline $\begin{array}{l}\text { Plated } \\
\text { sections }\end{array}$ & 28 & 1.16 & 1.03 & 1.13 \\
CHS & 8 & 1.19 & 1.08 & 1.09 \\
Mean & - & 1.17 & 1.05 & 1.12 \\
COV* & - & 0.11 & 0.07 & - \\
\hline
\end{tabular}

COV: coefficient of variation

Table I. Comparison of continuous strength method with cross-section compression tests and existing design guidance

\begin{tabular}{lcccc}
$\begin{array}{l}\text { Section } \\
\text { type }\end{array}$ & $\begin{array}{l}\text { Number } \\
\text { of tests }\end{array}$ & $M_{\mathrm{u}, \text { test }} / M_{\mathrm{u}, \mathrm{EC} 3}$ & $M_{\mathrm{u}, \text { test }} / M_{\mathrm{u}, \mathrm{CSM}}$ & $M_{\mathrm{u}, \mathrm{CSM}} / M_{\mathrm{u}, \mathrm{EC} 3}$ \\
\hline $\begin{array}{l}\text { Plated } \\
\text { sections }\end{array}$ & 32 & 1.18 & 1.02 & 1.17 \\
CHS & 43 & 1.13 & 1.00 & 1.13 \\
Mean & - & 1.15 & 1.01 & 1.15 \\
COV* & - & 0.10 & 0.08 & - \\
\hline
\end{tabular}

COV: coefficient of variation

Table 2. Comparison of continuous strength method with inplane bending tests and existing design guidance 


\section{APPLICATION TO OTHER METALLIC STRUCTURES}

Materials that exhibit a high degree of non-linearity and strain hardening fit less appropriately into the framework of crosssection classification, and generally benefit to a greater extent from the continuous strength method. Such materials include aluminium, stainless steel and some high-strength, coldworked steels.

Application of the continuous strength method to aluminium, stainless steel and high-strength steel has been described by Gardner and Ashraf, ${ }^{22}$ and specifically to stainless steel by Gardner and Nethercot ${ }^{21}$ and Ashraf et al. ${ }^{28,29}$ For stainless steel, the pronounced strength enhancements that arise in the corner regions of cold-formed sections ${ }^{30}$ owing to high localised plastic deformation were also incorporated into the design method. Average increases in resistance over the existing methods (Eurocode) of around 30\% for stainless steel and $10 \%$ for aluminium were observed. Insufficient test results precluded an equivalent comparison for high-strength steels, but, given the comparable degree of non-linearity, similar results to those obtained for aluminium would be anticipated.

\section{CONCLUSIONS}

In the present paper, some shortcomings of the concept of cross-section classification have been highlighted, and, as an alternative treatment, the continuous strength method has been introduced. The continuous strength method is based on a continuous relationship between slenderness and (inelastic) local buckling and a rational exploitation of strain hardening. The level of enhancement in resistance offered by the continuous strength method over conventional design methods for steel structures has been found to be approximately $12 \%$ for cross-section compression strength and 15\% for in-plane bending strength, and there is also a reduction in scatter of the predictions. An additional benefit of the proposed approach is that cross-section deformation capacity is explicitly determined in the calculations, thus enabling a more sophisticated and informed assessment of ductility supply and demand. Further developments of the method are under way.

\section{ACKNOWLEDGEMENTS}

The author would like to thank Professor David Nethercot, Dr Mahmud Ashraf and Andrzej Lakomy for their contribution to related research.

\section{REFERENCES}

1. AKiYAma H., KuWAmuRa H., Yamada S. and ChiU J. Influences of manufacturing processes on the ultimate behaviour of box-section members. Proceedings of the $3 \mathrm{rd}$ Pacific Structural Steel Conference (PSSC), Tokyo, Japan, 1992, 313-320.

2. FENG M., WANG Y. C. and DAVIES J. M. Structural behaviour of cold-formed thin-walled short steel channel columns at elevated temperatures. Part 1: Experiments. Thin-Walled Structures, 2003, 41, No. 6, 543-570.

3. GE H. and UsAmI T. Strength of concrete-filled thinwalled steel box columns: experiment. Journal of Structural Engineering, ASCE, 1992, 118, No. 11, 3036 3054.

4. HAN L., TAO Z., Huang H. and ZHAO X. Concrete-filled double skin (SHS outer and CHS inner) steel tubular beamcolumns. Thin-Walled Structures, 2004, 42, No. 9, 1329 1355.

5. TAO Z., HAN L. and WANG Z. Experimental behaviour of stiffened concrete-filled thin-walled hollow steel structural (HSS) stub columns. Journal of Constructional Steel Research, 2004, 61, No. 7, 962-983.

6. UY B. Local and post-local buckling of concrete filled steel welded box columns. Journal of Constructional Steel Research, 1998, 47, No. 1-2, 47-72.

7. JiRsA J. O., FOOK-Hoy L., Wilhoit J. C. and Merwin J. E. Ovaling of pipelines under pure bending. Proceedings of the Offshore Technology Conference, Houston, 1972, pp. $573-579$.

8. Rondal J., Boeraeve Ph., SedlaceK G., Stranghöner N. and LANGENBERG P. Rotation Capacity of Hollow Beam Sections. CIDECT, Research project No. 2P, 1995.

9. SchilLing G. S. Buckling strength of circular tubes. Journal of Structural Division, ASCE, 1965, 91, No. 5, 325-348.

10. Sedlacek G., Dahl W., Rondal J., Boreaeve Ph., STRANGHÖNER N. and KALINOWSKI B. Investigation of the Rotation Behaviour of Hollow Section Beams. ECSC Research project, final report, 7210/SA/119, 1995.

11. SHERMAN D. R. Tests of circular steel tubes in bending. Journal of the Structural Division, ASCE, 1976, 102, No. 11, 2181-2195.

12. SHERMAN D. R. Inelastic flexural buckling of cylinders. Proceedings of the Steel Structures Conference: Recent Advances and their Applications to Design, Budva, 1986, pp. 339-357.

13. Comité EuropéEn de Normalisation. EN 1993-1-1. Eurocode 3: Design of steel structures. Part 1-1: General rules and rules for buildings. CEN, Brussels, 2005.

14. GARDNER L. and CHAN T. M. Cross-section classification of elliptical hollow sections. Steel and Composite Structures, 2007, 7, No. 3, 185-200.

15. CHAN T. M. and GARDNER L. Bending strength of hot-rolled elliptical hollow sections. Journal of Constructional Steel Research. doi: 10.1016/j.jcsr.2007.11.001 (in press).

16. Faella C., Mazzolani F. M., Piluso V. and Rizzano G. Local buckling of aluminium members: testing and classification. Journal of Structural Engineering, ASCE, 2000, 126, No. 3, 353-360.

17. ElChalaKani M., ZHAO X.-L. and GRZebieta R. Tests on concrete filled double-skin (CHS outer and SHS inner) composite short columns under axial compression. ThinWalled Structures, 2002, 40, No. 5, 415-441.

18. O'SHEA M. D. and BRIDGE R. Q. Local buckling of thinwalled circular steel sections with or without internal restraint. Journal of Constructional Steel Research, 1997, 41, Nos 2-3, 137-157.

19. GARDNER L. and Nethercot D. A. Experiments on stainless steel hollow sections-Part 1: Material and cross-sectional behaviour. Journal of Constructional Steel Research, 2004, 60, No. 9, 1291-1318.

20. Mazzolani F. M. Aluminium Alloy Structures, 2nd edn. E Et FN Spon, London, 1995.

21. GARDNER L. and Nethercot D. A. Stainless steel structural design: a new approach. The Structural Engineer, 2004, 82, No. 21, 21-28.

22. GARDNER L. and ASHRAF M. Structural design for non-linear 
metallic materials. Engineering Structures, 2006, 28, No. 6, 926-934.

23. Nethercot D. A. and LaWson R. M. Lateral Stability of Steel Beams and Columns: Common Cases of Restraint. The Steel Construction Institute, Ascot, 1992, SCI Publication 093.

24. Kemp A. R., Byfield M. P. and Nethercot D. A. Effect of strain hardening on flexural properties of steel beams. The Structural Engineer, 2002, 80, No. 8, 29-35.

25. Comité EuropéEn de Normalisation. EN 1993-1-5. Eurocode 3: Design of steel structures-Part 1-5: Plated structural elements. CEN, Brussels, 2006.

26. Byfield M. P. and Nethercot D. A. An analysis of the true bending strength of steel beams. Proceedings of the Institution of Civil Engineers, Structures and Buildings, 1998, 128, No. 2, 188-197.
27. SCHAFER B. W. Local, distortional, and Euler buckling of thin-walled columns. Journal of Structural Engineering, ASCE, 2002, 128, No. 3, 289-299.

28. Ashraf M., Gardner L. and Nethercot D. A. Compression strength of stainless steel cross-sections. Journal of Constructional Steel Research, 2006, 62, No. 1-2, $105-115$.

29. Ashraf M., Gardner L. and Nethercot D. A. Structural stainless steel design: Resistance based on deformation capacity. Journal of Structural Engineering, ASCE, 2008, 134, No. 3, 402-411.

30. AShraf M., GARDNER L. and Nethercot D. A. Strength enhancement of the corner regions of stainless steel crosssections. Journal of Constructional and Steel Research, 2005, 61, No. 1, 37-52.

\section{What do you think?}

To comment on this paper, please email up to 500 words to the editor at journals@ice.org.uk

Proceedings journals rely entirely on contributions sent in by civil engineers and related professionals, academics and students. Papers should be 2000-5000 words long, with adequate illustrations and references. Please visit www.thomastelford.com/journals for author guidelines and further details. 